\title{
Para além da História: Campo de Trânsito de João Paulo Borges Coelho
}

\author{
Nazir Ahmed Can \\ Universitat Autònoma de Barcelona
}

RESUMO: FOCALIZANDO A TEORIA PÓS-COLONIAL E ALGUMAS DAS SUAS APORIAS (EXCESSIVA DEPENDÊNCIA DE UMA LEITURA MIMÉTICA DO TEXTO, SOBREVALORIZAÇÃO DA BIOGRAFIA, "ESQUECIMENTO" DAS PRESSÕES EDITORIAIS E INSTITUCIONAIS), PRETENDE-SE, A PARTIR DA ANÁLISE DE CAMPO DE TRÂNSITO (2007), DE JOÃO PAULO BORGES COELHO, VERIFICAR DE QUE MODO A ESCRITA PRODUZIDA EM ÁFRICA PODE SUBVERTER E CONFUNDIR AS PREMISSAS DISCURSIVAS DOS ESTUDOS PÓS-COLONIAIS DE ORIENTAÇÃO CLÁSSICA. COM BASE EM SUBSÍDIOS TEÓRICOS DE GIORGIO AGAMBEN, OBJETIVA-SE ILUSTRAR ALGUMAS DAS INTENÇÕES DO PROJETO ESTÉTICO DO AUTOR MOÇAMBICANO.

ABSTRACT: FOCUSING ON THE POSTCOLONIAL THEORY AND SOME OF ITS APORIAS (STRONG DEPENDENCY ON A MIMETIC READING OF THE TEXT AS REPRESENTATION OF REALITY AND HISTORY, OVERRATING OF THE AFRICAN AUTHOR'S BIOGRAPHY, "FORGETTING" THE EDITORIAL PRESSURES THAT FALL UPON THEM), WE WILL TRY TO EXPLAIN, FROM THE ANALYSIS OF CAMPO DE TRÂNSITO (JOÃO PAULO BORGES COELHO, 2007), HOW THE WRITING PRODUCED IN AFRICA CAN SUBVERT AND MISLEAD THE DISCURSIVE PREMISE OF THE CLASSICALLY-ORIENTED POSTCOLONIAL STUDIES. WE WILL BORROW THE THEORETICAL BASIS FROM GIORGIO AGAMBEN TO ILLUSTRATE SOME OF JOÃO PAULO BORGES COELHO'S AESTHETIC PROJECT.

PALAVRAS-CHAVE: TEORIA PÓS-COLONIAL; APORIAS, JOÃO PAULO BORGES COELHO, GIORGIO AGAMBEN.

KEYWORDS: POSTCOLONIAL THEORY, APORIAS, JOÃO PAULO BORGES COELHO, GIORGIO AGAMBEN. 


\section{A ambivalência de fuga: Algumas considerações sobre a crítica e a obra}

A crítica pós-colonial tende a entregar à escrita produzida em África uma função de subversão às práticas coloniais, atitude que cristalizaria uma libertação concreta das antigas colónias face ao imaginário prevalecente durante o período que antecede as independências políticas no continente. O termo pós-colonialismo englobaria, assim, as estratégias discursivas e performativas que frustram a visão colonial (MOURA, 1999, p. 9), que recusam a herança imposta pelo colonizador (ASHCROFT, 1989, p. 38) ou que as dessacralizam (GLISSANT, 1981, p. 192). Sem querer minimizar a importância de ditas aproximações ${ }^{1}$, cremos que o enfoque crítico que delimita a escrita africana somente a partir de uma recusa é redutor. Parece-nos claro que ao adotarmos uma postura semelhante incorreríamos no risco de reduzir estas literaturas a uma mera função de acompanhamento da História, condenando-as praticamente a um exercício de reação; além disso, seguindo esta visão, o adversário seria sempre o mesmo, o heterogêneo passado colonial. Por outro lado, se é certo que Homi Bhabha entrega à questão da ambivalência na literatura póscolonial uma especial relevância (questionando, em parte, esta rígida polarização), também é evidente que no centro da sua análise reside apenas a relação que o colonizador mantém com o colonizado, sendo este último, simultaneamente, objeto de desejo e derrisão (BHABHA, 1994, pp. 85-92)². Apesar da importância desta estratégia, parece-nos que ela não é exclusiva. No nosso entender, conviria acrescentar a esta proposta dois tipos de aproximações: 1) uma postura crítica que dê conta da ambivalência criada no sentido inverso desta relação, isto é, do antigo colonizado face ao antigo colonizador, reconhecendo a mútua imbricação no processo de formação cultural. Como refere Gikandi, "the colonized space was instrumental in the invention of Europe just as the idea of Europe was the condition for the possibility of

1 Que, diga-se, nos últimos anos começaram já a ser revistas no próprio seio da diversificada crítica pós-colonial, sobretudo por aquela de orientação mais materialista (C. Achebe, A. Mbembe, A. Appadurai, G. Huggan, etc.).

2 A "mimicry", que está na base desta estratégia, resumir-se-ia na cópia incompleta e ambígua que o colonizado oferece do colonizador. No afã daquele em se parecer a este, ativam-se gestos que, no entanto, mais do que um efeito de semelhança, produzem uma representação caricata e parcial do próprio colonizado. 
the production of modern colonial and postcolonial society" (GIKANDI, 1996 , p. 26). Encontramos esta estratégia, por exemplo, em Visitas do Dr. Valdera (2004) de João Paulo Borges Coelho (a partir de agora, JPBC). Conviria, pois, que esta recíproca relação não fosse ocultada sob o manto da influência unilateral; 2) uma maior atenção à ambivalência de fuga que escapa à dicotomia (colonizador/colonizado), já que nada obriga o escritor africano a centrar a sua visão pessoal do mundo directamente nestes dois polos.

Campo de Trânsito (2007) parece enquadrar-se nesta última hipótese, já que não existe nenhuma referência que localize a narrativa numa espaçotemporalidade concreta. A tendência a situar esta obra unicamente no período pós-independência e nos campos de reeducação criados pela Frelimo pode pecar por abusiva, visto que não valoriza o afã do autor em promover uma comunicação entre o local e o universal. Além disso, a estratégia alegórica adotada nesta obra aguça a sua ambiguidade, dado que em lugar de referentes reais, verificamos a inserção de pessoas-bestas que podem pertencer, como sabemos, a qualquer contexto. Ao mesmo tempo, a ambiguidade não é inscrita apenas na estrutura interna da narrativa (sobredeterminação de discursos), mas prolonga-se no paratexto (ausência de glossários, capa escura sem a excessiva ênfase das cores presentes nos anteriores romances), orientando ainda a reflexão para a recepção que a obra poderá viabilizar. Como sempre, afinal, cabe-nos perguntar: quem são os leitores de JPBC? Quem consome as suas alegorias? É Gayatri Chakravorty Spivak, crítica de referência da teoria pós-colonial, quem alerta: "For me, the question 'Who should speak?' is less crucial than Who shall listen?" (SPIVAK, 1990, p. 59). Estas questões adquirem especial relevância se analisarmos Campo de Trânsito, onde a opção pelo uso de um português clássico sem deslizamentos locais, além da ausência de referências topográficas e cronológicas diretas, parece anunciar o ensejo de um questionamento que ultrapassa o "histórico". Sugerimos, nesta medida, que Campo de Trânsito pode fundar-se em questões locais, mas terá sempre desígnios globais, recuperando a feliz fórmula que dá título a um estudo de Walter Mignolo (2000).

3 Em que o jovem Vicente mascara-se de branco (Doutor Valdez) de forma a satisfazer a nostalgia que o médico provocava nas duas irmãs portuguesas, que formam, por sua vez, a família possível do jovem moçambicano. Neste ato, o jovem moçambicano dá corpo a uma figura portuguesa do passado colonial, cruzando e desfigurando dois tempos e duas personalidades num mesmo e caricato movimento. 
Diríamos inclusive que JPBC, em face desta escolha, propõe um novo olhar para a literatura moçambicana: utilizando o mercado que lhe dá relativa visibilidade (Editorial Caminho), o autor não deixa de subverter a sua lógica homogeneizante, já que não cumpre com o horizonte de expectativa editorial existente à volta do "autor africano". Como se sabe, o glossário, apesar da sua importância para a recepção mais completa do universo linguístico e sociocultural presente nos textos, constitui também uma insidiosa arma editorial que se alimenta da "cor local" africana e de uma moda de consumo com claras adjacências exóticas. A opção por uma escrita sem um referente espaçotemporal concreto e sem glossários explicativos obriga ainda o leitor a rever as típicas oposições binárias anunciadas pela historiografia clássica e a deslocar o seu olhar para o texto. O autor encontra, assim, uma sutil maneira de posicionar-se no "centro" das operações, interrogando o que realmente lhe interessa: o lado humano ocultado nas sombras abandonadas da(s) História(s).

Além disso, ao ligarmos Campo de Trânsito automaticamente ao período pós-independência moçambicano, incidiríamos ainda naquilo a que Locha Mateso denomina "théorie du reflet", ou seja, na análise que parte da componente biográfica do autor (moçambicano e historiador) para a interpretação temática da obra. Para Mateso, a imensa maioria dos críticos abstém-se de analisar a problemática da separação e da subversão que a literatura pode imprimir à realidade, dado que as obras são pouco abordadas na sua qualidade de objeto estético. (MATESO, 1986, p. 199). A própria estratégia em introduzir na narrativa irônicos toques de fábula pode desembocar tanto na História como fora dela, já que a mesma se insinuará na intimidade física e psicológica das personagens, sendo que estas, por sua vez, são desprovidas de qualquer biografia. Assim, como podemos afirmar sem reservas que a obra recria os campos de reeducação moçambicanos sem desrespeitar o pacto ficcional proposto pelo autor?

Centraremos a nossa análise na recorrente questão do corpo, de forma a verificar que a fronteira entre a História e a Filosofia é líquida na estética de JPBC. Emprestaremos da teoria de Giorgio Agamben e da sua vasta obra sobre filosofia política alguns subsídios teóricos que, longe de minimizar a especificidade literária da escrita do autor moçambicano, constituirão importantes chaves de interpretação para iluminar o seu projeto estético. 


\title{
2. O corpo da lei no corpo do Homem: na solidão do Campo de Trânsito
}

\begin{abstract}
A lei tem ouvidos pra te delatar/ Nas pedras do teu próprio lar/ (...) A lei te vigia, bandido infeliz/ Com seus olhos de raios X/ (...). A lei te procura amanhã de manhã / Com seu faro de dobermam/ (...) A lei fecha o livro, te pregam na crug/ depois chamam os urubus/ (...) A lei logo vai te abraçar infrator/ Com seus braços de estivador
\end{abstract}

"Hino de Duran", Chico Buarque (Ópera do Malandro, 1979)

"Hino de Duran", de Chico Buarque, nasce num contexto de ditadura militar que durante duas décadas altera profundamente a estrutura da sociedade brasileira, assolando-a. O compositor, músico e escritor brasileiro, nesta letra incluída em Ópera do Malandro (1979), entrega corpo à abstração que é a base característica da lei: alertando para a existência de um norma que possui "ouvidos" e que se impregna nas paredes das casas mais quotidianas, sugerindo ainda que a mesma tem "olhos de raio X", "faro" canino e "braços de estivador", Chico Buarque põe a nu uma lei com poder de sacrificar (pregando na cruz), sem um fundamento legal ("a lei fecha o livro"). Em suma, uma lei que se infiltra no humano e que se afirma na exceção.

Poderíamos estabelecer uma ponte entre esta interpretação e a vida de Mungau em Campo de Trânsito. Tendo sido capturado sem motivo aparente no interior da sua própria casa, a personagem faz uma viagem cujo primeiro destino é uma prisão, onde pernoita. Deste estabelecimento prisional Mungau é enviado para o Campo de Trânsito, espaço provisório, como o próprio nome indica: neste "fim do mundo" (JPBC, 2007, p. 63) se decide se os prisioneiros são mandados para o Campo Novo ou o Campo Antigo. Experimentando a exposição total dos seus movimentos, Mungau torna-se num elemento mais desta espécie humana que é agarrada por uma lei que se serve do homem para depois o isolar e o desnudar, colocando-se precisamente fora e acima de si própria, no espaço soberano da exceção.

Seguindo o rastro de Foucault e dos seus estudos sobre o biopoder e a biopolítica, Agamben teoriza a relação de interdependência entre a norma e a exceção. Para ele, em Homo Sacer: Il potere sovrano e la nuda vita (1998), a relação entre o poder soberano e a vida nua é uma relação de captura, viabilizada 
por uma estrutura de exceção. Esta lei aplica-se em conformidade com seu próprio bando: mantendo-se na própria privação, aplica-se a partir do desvio (AGAMBEN, 1998, p. 47). O filósofo italiano orienta a sua reflexão sobre a vida nua a partir da separação (proveniente da Grécia antiga) entre bios e zoé. Bios representa a forma ou o modo de viver apropriado a um indivíduo ou grupo; zoé, por sua vez, constitui o simples fato de viver, algo estritamente biológico e comum a todos os seres vivos, sejam eles animais, homens ou deuses (AGAMBEN, 1998, p. 9). O advento biopolítico do poder não seria recente, como defende Foucault, para quem, desde a Revolução Francesa a vida passa a estar no cerne das preocupações políticas (FOUCAULT, 1997, p. 261), mas sim um acontecimento muito mais antigo: desde o momento em que os gregos fundam a polis, integrando na ordem jurídica a zoé apenas sob uma forma de exclusão, a vida passa a ser alvo de exceptio. A partir deste fenômeno aparentemente contraditório (da inclusão excludente e da exclusão inclusiva), Agamben identifica não só o corpo biológico de toda uma tradição política, mas também uma figura simétrica a este poder: o homo sacer, ou o homem sagrado (imagem inspirada numa obscura figura do Direito romano arcaico), que pode ser morto, mas não sacrificado. (AGAMBEN, 1998, p. 93). Finalmente, o campo de concentração representa o espaço da exceção na história recente de um modo particularmente completo. No campo (enquanto nomos ou o modelo oculto do moderno), a vida nua do homo sacer (como, por exemplo, o judeu) é isolada, e este pode ser morto, mas não sacrificado; a exceção converte-se em regra (AGAMBEN, 1998, p. 215), fazendo com que os limites (interior e exterior, natureza e cultura, direito e fato) se dissolvam.

A vida de Mungau parece enquadrar-se nestas premissas. O seu estatuto, preso apenas por ter sido acusado, sugere o paradoxo fundamental da norma: no preciso momento em que não é aplicada, assume maior influência. Compete à personagem Bexigoso a missão de representar o Estado na captura dos diversos "mungaus" espalhados pela cidade:

Só a um deles - o que falou - parece conhecer vagamente, dos bares ou porque tem uma figura fora do comum. Aos outros dois nunca viu (...). É maciço, um tudo-nada gordo até, pescoço taurino, cabeça rapada. Bexigoso. Mas o que verdadeiramente impressiona são os olhos. Não têm cor, quase brancos, incluindo 
as pupilas. Nunca viu umas pupilas assim. Duvida até que ele possa ver alguma coisa com aquilo. (JPBC, 2007, pp. 10,11)

Curiosamente, Bexigoso é o único (dos três homens) que Mungau parece reconhecer, talvez devido a sua bizarra figura. Estranheza e familiaridade conjugam-se nele, o unheimlich freudiano parece encontrar nesta personagem um ilustre representante. A utilização do pronome demonstrativo "aquilo" (e não "isto") indicia mesmo que os seus olhos pertencem a uma outra esfera. Além disso, a descrição de Bexigoso, sustentada em elementos humanos e animais ("pescoço taurino"), revela a comunhão destes dois universos e, por conseguinte, a sobrevivência do estado natural no seio do Estado. A dúvida quanto àquilo que vê também não é casual: os seus olhos sem cor sugerem exatamente a cegueira do poder, a sua incapacidade para ser onipresente. Para Foucault, o poder não pode ser visto, de nenhuma maneira, como onipotente ou onisciente: se as relações de poder produziram formas e análises de investigação é precisamente porque o poder não é onisciente, mas sim cego (FOUCAULT, 1999, p. 625). O filósofo francês acrescenta ainda que o fato de assistirmos ao desenvolvimento de tantas forças de poder, de tantos sistemas e formas de vigilância, é porque precisamente o poder é sempre impotente (ibid.). Naturalmente, quando Foucault afirma que o poder soberano é cego e impotente, não pretende afirmar que o mesmo tenha perdido a sua eficácia, já que a sua impotência é ontológica. As pupilas do Bexigoso representam tanto impossibilidade da visão como aquilo que nelas não se pode ver totalmente.

Assim, o poder cego representado em Campo de Trânsito está abaixo do visível, como indiciam as bolas do malabarista, cuja totalidade dos movimentos a pequena janela do Director não pode controlar: "Sem se ver de onde vêm, como voam, para onde caem; riscando o ar em curtos e desconexos percursos, entrando e saindo do exíguo quadrado que os caixilhos da janela delimitam. Pequeno, diminuto fragmento da vida" (JPBC, 2007, p. 207); está ainda ligeiramente acima da matéria orgânica, podendo decretar vida e morte: "De dentro sai a praga geral e o aviso ao quase-atropelado de que tome mais cuidado, da rua a imprecação de quem quase morreu sem saber quem o matava" (JPBC, 2007, p. 14); e, claro, na intersecção de ambos. Por ser cego, o poder lê a matéria com as mãos, mas necessita comprovar os sinais que se escondem 
atrás dela. Assim, para cumprir a função que as "aranhas" não conseguem ver, Mungau é convocado:

Há dois campos junto da Aldeia (...) representados em duas das pastas que o Director tem no seu gabinete (...) Mais exactamente as pastas Quatro e Cinco, que as pequenas aranhas calcorreiam sem cessar à procura dos segredos que encerram. Mungau, o enviado, terá de descobrir aquilo que de longe as duas não conseguem ver, só suspeitar. (JPBC, 2007, p. 92)

Os sinais que o poder não consegue ver encontram-se, pois, no cruzamento da matéria (zoé) e do visível (bios). Para alcançar esta cruz totalizadora, o Director aciona os meios (Mungau enquanto vida nua) e as técnicas de manipulação que lhe estão ao seu dispor. Não há, neste sentido, uma explicação fisiológica (compensatória) ou uma causa misteriosa (mágica) para o poder absoluto do Director: "E o prisioneiro segue-o como se estivesse enfeitiçado. Não o está, obviamente, porque na racionalidade do Campo de Trânsito não existe espaço para fenómenos desse tipo" (JPBC, 2007, p. 56). Nesta medida, o corpo é posto ao serviço da realidade, tornando-se testemunho de uma lei fabulada pela própria animalização do soberano: "Mungau, olhando as duas mãos anichadas uma na outra, preocupa-se. Não faz ideia do que poderá resultar do acasalamento entre uma aranhazinha e um sapo imberbe e gordo" (JPBC, 2007, p. 62). O aperto de mãos entre o Director e Bexigoso é metaforizado ironicamente, como se se tratasse de um bizarro ato sexual (e de procriação) entre a aranha e o sapo. Como se sabe, a alegoria aparece frequentemente para personificar ou animalizar um valor abstrato, um valor que não é especificado retoricamente na descrição ou na narração. As "aranhas" do Director, repetitivamente rememoradas na narrativa, e o "sapo imberbe" (de Bexigoso) revelam a ascendente despersonalização soberana e a sua constante metamorfose, que estão na base do encarceramento do indivíduo contemporâneo. A ligação num único corpo entre o soberano e a besta, além da perversa lógica que está por trás desta conexão, permite ainda uma reflexão sobre os limites exteriores à ordem humana e à liberdade individual, temáticas sobre as quais se alicerça toda a narrativa.

Por outro lado, inúmeras são as passagens que referem o "velho bicho" que Mungau "traz dentro" de si e que deve "domar" para poder enfrentar a 
realidade que se lhe depara ${ }^{4}$. A hierarquização da vida (nutritiva, sensitiva e intelectiva), fundada na Grécia antiga por Aristóteles e que representa o caráter originário do dispositivo biopolítico (AGAMBEN, 1998, p. 11), é recriada insistentemente no corpo do protagonista. Nas escadas do seu apartamento, quando é apreendido, referencia-se pela primeira vez a sua abstração olfativa. Isto é, para evitar o mau cheiro do lixo que nelas habita, Mungau prende a respiração e passa incólume à desagradável sensação: "Fá-lo automaticamente, sem que tal requeira um esforço consciente. Fê-lo também desta vez apesar das circunstâncias excepcionais em que se encontra" (JPBC, 2007, p. 12). A divisão do ser em zoé e bios e o seu posterior contacto são claramente expostos nos dois segmentos separados pelo ponto final. Se no primeiro caso o protagonista age "automaticamente", sem necessidade de um "esforço consciente" (de acordo, pois, com a zoé que lhe é particular), no segundo, Mungau também o faz, "apesar das circunstâncias excepcionais" e (bio) políticas em que se vê envolvido.

Ao mesmo tempo, é notória a preocupação do protagonista em não ser um prisioneiro comum. Apesar de vivenciar a exposição total, Mungau jamais cede àquele que o oprime e tenta evitar que os seus gestos mais íntimos sejam observados por estranhos, já que esta situação consolidaria a sua subalternidade. No entanto, o símbolo histórico (o destino fundamentalmente político) infiltra-se no próprio sensível (corpo, gestos). Antes de ser transferido para o Campo de Trânsito, Mungau passa um dia numa pequena cela. Abandonado à mais absoluta perplexidade, socorre-se da imaginação para amenizar a solidão, inventando um cenário e uma plateia que o observa. Por um lado tenta cativar um olhar piedoso dos assistentes, para quem ele seria a vítima de uma absurda injustiça; por outro, antecipa uma vergonha maior: "Como será quando for preciso chorar? Quando for inadiável a necessidade de se servir do balde dos excrementos? (JPBC, 2007, p. 19)". A vigilância dos gestos corporais mais íntimos (chorar), ou mesmo daqueles que se referem à esfera fisiológica (excrementos), apresenta-se, portanto, como um elemento básico de poder na teia em que se vê enredado. No palco da cela, "humildade" e "dignidade" tornam-se, pois, categorias incompatíveis. Ao receber o pedaço de pão a que tem direito, o protagonista "(...) guarda para comer mais tarde,

4 Vejam-se alguns exemplos nas páginas 19, 43, 70, 91, 115, 125, 182, 197, 198, 201. 
quando estiver só. Custa-lhe roer aquela miserável dádiva na presença do seu captor. No teatro que há pouco criou a sua dignidade soa agora muito forte" (JPBC, 2007, p. 21). A vida biológica e a vida política encontram-se, deste modo, numa zona indefinida, acentuada pela utilização dum léxico específico de caça ("captor") e animalização ("roer"), para além do recurso ao oximoro ("miserável dádiva"). O termo "dádiva”, aliás, proveniente do latim, significa não só aquilo que se dá gratuitamente (datìvum), mas também algo que pode supor uma tentativa de aproveitamento ou suborno (debìta). Convém ainda referir que este oximoro antecipa a perversa manipulação que sofrerá Mungau no Campo de Trânsito por via de pequenas e miseráveis dádivas (colher, caderno, lápis) que terão esta dupla função. A cela funciona, pois, como um "estágio", um primeiro trânsito para a realidade que provará a posteriori no Campo. JPBC, conscientemente ou não, une dois nomos do moderno: a prisão, teorizada por Foucault (1975) e o campo, concebido Giorgio Agamben (1998).

No entanto, Mungau não se apercebe de pronto que a sua condição comporta já sinais de irreversibilidade, que o seu destino está de antemão traçado e que a categoria "dignidade" só pode ser concebida por ele próprio, mas nunca na relação com a realidade do Campo. Ela de pouco lhe serve desde que ele se tornou presa, já que lei do Campo pertence a uma lógica de "reivindicação quase biológica de pertença" (ANTELME, 1957, p. 12), da qual já participa ativamente. A dignidade, que está na confluência mesma do jurídico e do moral, carece não só de utilidade prática neste contexto, como também a reiteração da sua inutilidade alerta para um fato mais inquietante: a vida pode prosseguir e organizar-se numa esfera em que a ela não faça parte. Parece ser esta a indagação primeira da obra: como foi possível ter-se chegado aqui? Assim, se há algum destino para Mungau, este passa pela íntima relação que a sua vida (nua) estabelecerá com o poder (soberano), situação descrita de forma económica na chegada à prisão: “Chegam finalmente ao destino” (JPBC, 2007, p. 16). A ideia universal de destino, muito presente em todo o texto, é aproveitada sutilmente pelo autor, que atualiza o seu potencial semântico nas frases aparentemente mais inocentes. Deste modo, o significado de "destino" pode rapidamente deslizar do simples lugar de chegada (meta espacial, instituição prisional) para o seu sentido mais amplo: encadeamento de acontecimentos considerado necessário e fatal, produzido por uma força que está acima dos homens e das coisas (fatalidade inelutável, poder soberano). A partir de então, 
o protagonista passa a pertencer a uma dimensão que até então desconhecia, sendo incluído numa espécie de rebanho: "J. Mungau, sempre tão seguro de si, agora manso e vulnerável como um cordeiro!” (BC, 2008, 18).

O Campo de Trânsito, como espaço da exceção absoluta, sintetiza todos os aspetos vivenciados na cidade e na prisão. Trata-se do lugar por excelência da ambivalência, onde interior e exterior se confundem até ao ponto do prisioneiro sentir-se, por vezes, mais livre dentro das suas fronteiras do que fora delas: "Estão já oficialmente no espaço do campo, Mungau voltou a ser o prisioneiro 15.6. Nada portanto o obriga a que permaneçam juntos" (JPBC, 2007, p. 121); esta ambiguidade é aguçada na conformação espacial: "Estranha aquela disposição, os guardas vivendo juntos numa camarata, os detidos em casinhas individuais" (JPBC, 2007, p. 42); no Campo, a vida nua sente ainda o paradoxo do exílio, ora visto como pena, ora visto como refúgio: "Descreve mentalmente este lugar quando está longe, e quanto mais exacta sente essa descrição mais nítida é a sensação de que está inventando uma nova casa" (JPBC, 2007, p. 122). Em suma, neste lugar, o próprio mito de Narciso é invertido e o homo sacer pode rapidamente esquecer-se de onde vem:

Mungau inclina-se sobre o rio, mergulha ali as mãos e lava o rosto, aproveitando para se olhar nas águas e tentar ver no que se tornou. Mas, pobre dele que não consegue ver mais que a vã visão do seu próprio reflexo! 'Será que os meus olhos se estão tornando claros?', pergunta-se com preocupação. 'Será que deixei de saber aonde pertenço?' (JPBC, 2007, pp. 121,122)

Assim, se durante toda a narrativa o protagonista é assaltado por dúvidas, que vão das mais ínfimas e aparentemente insignificantes ("De que será que me acusam?"5) às mais existenciais ("Onde estou? [...] Quem sou?" - JPBC, 2007, p. 7), no Campo, todos os seus gestos comportam uma dúvida inaugural, relacionados com a transformação ("Será que os meus olhos se estão tornando claros?") e mesmo com a origem ("Será que deixei de saber aonde pertenço?").

A porta entreaberta do Director resume a magnitude desta incerteza: "Mungau detém-se por um momento no umbral na dúvida se será mais

5 Várias são as ocorrências. Vejam-se as páginas 13, 14, 15, 18, 19, 20, 32. 
curial aguardar até ser chamado ou tomar a iniciativa de se anunciar (o guarda nada lhe disse a respeito)" (JPBC, 2007, pp. 57,58). O "umbral" é o lugar de abandono supremo do protagonista (a si mesmo e à lei), como sugere a escolha lexical: "curial" podendo significar "respeitoso", "conveniente", remete, ao mesmo tempo, à origem do termo, "Cúria", isto é, à corte do Papa ou aos tribunais pontifícios. Esta situação, de resto, é muito análoga àquela que experimenta Joseph K., protagonista de Processo, de Kafka. O espaço do já-aberto constitui em ambas as obras a ilustração espacial do estado de exceção, já que, como sugere Agamben, justamente por estar já aberta é que imobiliza, simboliza aquele preciso instante em que a lei nada prescreve (AGAMBEN, 1998, p. 69). Num universo carente de palavras e explicações ("o guarda nada lhe disse a respeito"), cabe ao gesto ou à performance do corpo a comunicação: "Chegam ao destino. O guarda indica a porta com um leve sinal de olhos e segue imediatamente para outras paragens, deixandoo só" (JPBC, 2007, p. 57). A porta entreaberta do Director não permite definir o dentro e o fora, o aquém e o além da norma, constituindo-se como o elemento topográfico da total indistinção: sintetiza não só o paradoxo da lei (nem aberta, nem fechada, nem interior, nem exterior) e das suas técnicas de manipulação e alienação (espaciais, gestuais), mas também o momento máximo de solidão que experimenta a personagem. Sem embargo, ao contrário de Joseph K., que nunca chega a atravessar esta fronteira porque um guarda não lhe permite a passagem, Mungau entra na sala do Director e, a partir deste momento, imerge na experiência da relação (de confronto e de servidão voluntária) com o poder.

A vida de Mungau, desde a sua captura até ao momento final da narrativa (deixada em aberta), corrobora uma dimensão humana presente em toda a obra de JPBC: o ser não pode reparar a opressão (histórica) sem transcendêla através da experiência. Notamos na parte final da trama (e na relação que mantém com a Mulher do Professor durante toda a narrativa) que uma responsabilidade para lá de suas condicionantes - física, psicológica, moral obriga algumas das suas personagens a superar a História, sendo que nesta obrigação há algo de infinito. Como refere Lévinas, o infinito reflete-se tanto no interior da totalidade e da História, como no interior da experiência (LÉVINAS, 1999, p. 49). Esta dimensão não é dada de antemão, mas produz-se de alguma maneira no seio mesmo de uma experiência individual. 
JPBC interroga o humano a partir da História e vice-versa. No entanto, a sua obra inscreve a História para poder transcendê-la. Identificar a sua escrita unicamente com "dados reais" seria castrar esta transcendência. O "real" constitui o mote para um questionamento mais amplo (e, logo, aberto), servindo de caminho, nunca de meta. É, portanto, na confluência entre uma experiência estético-filosófica e a realidade que lhe inspira que reside a posição ética de Campo de Trânsito: demarcando-a da exclusividade historicista, esta obra requer uma auto-interrogação, já não coletiva ou nacional, mas sim individual e desterritorializada.

\section{Referência Bibliográfica}

AGAMBEN, Giorgio. Homo sacer. El Poder soberano y la nuda vida; trad. A. Cuspinera, Valência: Pre-Textos, 1998.

ANTELME, R. L'Espèce humaine, Paris: Gallimard, 1957.

ASHCROFT, Bill, G. Griffiths e H. Tiffin. The Empire writes back: theory and practice in post-colonial literatures. Londres: Routledge, 1989.

BHABHA, Homi K.. The Location of culture, Londres: Routledge, 1994.

COELHO, J. P. Borges. Campo de Trânsito, Lisboa: Editorial Caminho, 2007.

FOUCAULT, Michel. "Il faut défendre la société": cours au Collège de France (1975-1976). Paris: Seuil, 1997.

- Obras Esenciales. Estética, ética y hermenéutica, Barcelona: Paidós, 1999. Surveiller et punir: naissance de la prison. Paris: Gallimard, 1975.

GIKANDI, Simon. Maps of Englishness: Writing Identity in the Culture of Colonialism. Nova Iorque: Columbia UP, 1996.

GLISSANT, Édouard. Le Discours antillais. Paris: Gallimard, 1981.

LÉVINAS, Emmanuel. Totalidad e Infinito, trad. D. Guillot, Salamanca: Sígueme, 1999. MATESO, Locha. La littérature africaine et sa critique. Paris: Karthala, 1986.

MIGNOLO, Walter. Local histories/global designs: colonialit, subaltern knowledges, and border thinking. Princeton: Princeton University Press, 2000.

MOURA, Jean-Marc. Littératures francophones et théorie postcoloniale. Paris: Presses universitaires de France, 1999.

SPIVAK, Gayatri Chakravorty. The Post-Colonial Critic: Interviews, Strategies, Dialogues, Londres: Routledge, 1990. 